\title{
BMJ Open Health impact assessment of air pollution in Valladolid, Spain
}

\author{
Mario Cárdaba Arranz, ${ }^{1}$ María Fe Muñoz Moreno, ${ }^{2}$ Alicia Armentia Medina, ${ }^{3}$ \\ Margarita Alonso Capitán, ${ }^{4}$ Fernando Carreras Vaquer, ${ }^{4}$ Ana Almaraz Gómez ${ }^{5}$
}

To cite: Cárdaba Arranz M, Muñoz Moreno MF, Armentia Medina $A$, et al. Health impact assessment of air pollution in Valladolid, Spain. BMJ Open 2014;4:e005999. doi:10.1136/bmjopen-2014005999

- Prepublication history for this paper is available online. To view these files please visit the journal online (http://dx.doi.org/10.1136/ bmjopen-2014-005999).

Received 1 July 2014 Revised 3 September 2014 Accepted 23 September 2014

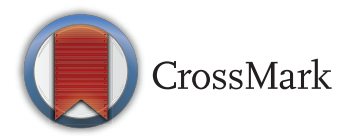

${ }^{1}$ Castilla y León Regional Health Service, Valladolid, Spain

${ }^{2}$ Research Support Unit, University Clinical Hospital, Valladolid, Spain

${ }^{3}$ Allergy Unit, Rio Hortega University Hospital, Valladolid, Spain

${ }^{4}$ Ministry of Health, Social Services and Equality, Madrid, Spain

${ }^{5}$ Medical Faculty, University of Valladolid, Valladolid, Spain

Correspondence to Dr Mario Cárdaba Arranz; mario00med@yahoo.es

\section{ABSTRACT}

Objective: To estimate the attributable and targeted avoidable deaths (ADs; TADs) of outdoor air pollution by ambient particulate matter $\left(\mathrm{PM}_{10}\right), \mathrm{PM}_{2.5}$ and $\mathrm{O}_{3}$ according to specific WHO methodology.

Design: Health impact assessment.

Setting: City of Valladolid, Spain (around 300000 residents).

Data sources: Demographics; mortality; pollutant concentrations collected 1999-2008.

Main outcome measures: Attributable fractions; ADs and TADs per year for 1999-2008.

Results: Higher TADs estimates (shown here) were obtained when assuming as 'target' concentrations WHO Air Quality Guidelines instead of Directive 2008/50/EC. ADs are considered relative to pollutant background levels. All-cause mortality associated to $\mathrm{PM}_{10}$ (all ages): 52 ADs (95\% Cl 39 to 64); 31 TADs (95\% Cl 24 to 39). All-cause mortality associated to $\mathrm{PM}_{10}(<5$ years): 0 ADs (95\% $\mathrm{Cl} 0$ to 1); 0 TADs (95\% $\mathrm{Cl} 0$ to 1). All-cause mortality associated to $\mathrm{PM}_{2.5}$ (>30 years): 326 ADs (95\% Cl 217 to 422); 231 TADs (95\% Cl 153 to 301). Cardiopulmonary and lung cancer mortality associated to $\mathrm{PM}_{2.5}$ (>30 years):

- Cardiopulmonary: 186 ADs (95\% Cl 74 to 280); 94 TADs (95\% Cl 36 to 148).

- Lung cancer : 51 ADs (95\% Cl 21 to 73); 27 TADs (95\% Cl 10 to 41).All-cause, respiratory and cardiovascular mortality associated to $\mathrm{O}_{3}$ (all ages):

- All-cause: 52ADs (95\% CI 25 to 77) ; 31 TADs (95\% Cl 15 to 45).

- Respiratory: 5 ADs (95\% Cl -2 to 13) ; 3 TADs (95\% $\mathrm{Cl}-1$ to 8$)$.

- Cardiovascular: 30 ADs (95\% Cl 8 to 51$) ; 17$ TADs (95\% Cl 5 to 30$)$.

Negative estimates which should be read as zero were obtained when pollutant concentrations were below counterfactuals or assumed risk coefficients were below one.

Conclusions: Our estimates suggest a not negligible negative impact on mortality of outdoor air pollution. The implementation of WHO methodology provides critical information to distinguish an improvement range in air pollution control.

\section{INTRODUCTION}

Numerous epidemiological studies conducted over the past decades point to adverse health impacts from exposure to

\section{Strengths and limitations of this study}

- Using ecological data to assume ambient pollutant concentrations as surrogates of individual exposure adds error.

- In addition, pollutant concentrations were not corrected for sub-Saharan dust intrusions.

- Cls only cover statistical uncertainty related to the risk estimates from the concentrationresponse functions (CRFs), currently under review by the WHO, while further uncertainty is added due to potential errors in assuming the general shape of CRFs, background pollutant levels, selection of health outcomes and structure of monitoring network.

- In sensitivity analysis, we considered different $\mathrm{PM}_{2.5} / \mathrm{PM}_{10}$ ratios, background concentrations and exposure-response relationships.

- It is difficult to generalise results to other populations as data were obtained from only one city.

outdoor air pollution, attributing the most severe health effects to particulate matter $(\mathrm{PM})^{1}{ }^{2}$ and, to a lesser extent, ozone ${ }^{3}\left(\mathrm{O}_{3}\right)$. New studies incorporate to the growing body of evidence, ${ }^{4-6}$ currently under review by the WHO through projects such as REVIHAAP (Review of evidence on health aspects of air pollution) and HRAPIE (Health risks of air pollution in Europe), confirming that outdoor air pollution is an important risk factor for health. ${ }^{78}$

According to the WHO, in the year 2012, ambient air pollution was responsible for 3.7 million deaths, representing $6.7 \%$ of the total deaths. Worldwide, ambient air pollution is estimated to cause about $16 \%$ of the lung cancer deaths, $11 \%$ of chronic obstructive pulmonary disease deaths, more than $20 \%$ of ischaemic heart disease and stroke, and about $13 \%$ of respiratory infection deaths. ${ }^{9}$ Recently, the International Research Agency on Cancer (IARC) classified air pollution mixture and PM as carcinogenic to human beings (Group 1). ${ }^{10}$

It could be expected that the impact caused by a preventable risk factor would decline if the exposure to that risk factor could be 
reduced or removed. According to this approach, the proportional reduction in the number of health problems or deaths as a result of reducing the risk factor is known as the attributable fraction $(\mathrm{AF}) .{ }^{11}$

Estimating the environmental burden of disease associated with exposure to air pollution is critical information for policymakers who can define strategies and prioritise actions by considering the health gains that could be achieved if the exposure to the risk factor were reduced to a 'target' concentration. ${ }^{1}$

We estimated the burden of mortality from exposure to $\mathrm{PM}_{10}, \mathrm{PM}_{2.5}$ and $\mathrm{O}_{3}$ at the city of Valladolid, as a health impact assessment (HIA) under various exposure scenarios in order to provide quantitative information of the potential benefits of reducing the exposure to these pollutants.

\section{METHODS}

\section{Calculation of burden of mortality}

On the basis of the method outlined by the WHO in the Environmental Burden of Disease (EBD) series ${ }^{12}$ we followed a classical risk assessment approach:

1. Determination of the ambient exposure of the population using data from model estimates or monitoring networks. A 'counterfactual' background or target concentration is also needed to determine the attributable disease or the potential gains of a reduction strategy.

2. Number of people exposed to air pollutants.

3. Baseline incidence of the adverse health outcomes associated with air pollutants (eg, the mortality rate in the population).

4. Concentration-response functions (CRFs) that relate changes in air pollutants concentrations with changes in the incidence of adverse health effects.

\section{Assessment of the ambient exposure of the population}

About 300000 people live in Valladolid, a Spanish city located at an altitude of $698 \mathrm{~m}$ in the Inner Plateau, $200 \mathrm{~km}$ North to Madrid. The orography of this plateau surrounded by mountains except on the border with Portugal favours winds penetrating from the Atlantic Ocean and on the contrary prevents or greatly reduces air circulation to and from the Bay of Biscay and the Southern Plateau. Notably, the Central System Range isolates Valladolid from the influence of Madrid as a great source of precursors, at least respecting direct transport at surface level. The climate is continental, with cold winters and dry summers. The pollution levels are strongly dependent on the atmospheric synoptic conditions, in this case a long and cold winter, with frequent fog events. The type of surface that surrounds the city is basically rough, bare and dry soil used primarily for agriculture. The urban aerosol corresponds to a lightly industrialised city whose contamination mostly comes from road traffic and domestic heating. Regarding economic activity, automotive sector is an important manufacturing industry. As natural sources of PM affecting occasionally the area, wildfires and wind-blown dustlike Saharan intrusions can be included. Regarding ozone, orography and solar radiation favour ozone formation and accumulation. No municipal emission source inventory has been developed yet. ${ }^{13-15}$

$\mathrm{PM}_{10}$ concentrations (annual means) were obtained from the annual reports 1999-2008 published by the Environmental Health Unit (EHU) of the city council responsible for the municipal fixed-site monitoring stations network. ${ }^{16} \mathrm{O}_{3}$ concentrations (daily maximum $8 \mathrm{~h}$ means) were provided on request to the EHU.The annual mean concentrations from the operating stations with a minimum data capture of $90 \%$ (operating stations with valid data according to regulatory standards) ${ }^{17-19}$ for the 10 years of data 1999-2008 were averaged to develop the following annual average estimates for $\mathrm{PM}_{10}$ and $\mathrm{O}_{3}: 35.41$ and $141.38 \mu \mathrm{g} / \mathrm{m}^{3}$, respectively. As there were no direct measures of $\mathrm{PM}_{2.5}$, they were estimated by applying the recommended $\mathrm{PM}_{2.5} / \mathrm{PM}_{10}$ ratio of 0.73 for Europe. ${ }^{1}$ Hence, the estimated concentration for $\mathrm{PM}_{2.5}$ was $25.85 \mu \mathrm{g} / \mathrm{m}^{3}$. Table 1 provides a scope of our exposure data set.

\section{Population exposed and mortality data}

Annual population figures from the municipal register and annual deaths by different causes and age groups (underlying causes of death selected according to $\mathrm{WHO}^{1} 8^{20}$ and coded in accordance with the International Classification of Diseases (ICD) 10th version), extracted from the Spanish Statistical Office for 1999-2008, ${ }^{21}$ were averaged and rounded off to the nearest whole number to obtain population and mortality figures for different age groups. In doing so, respiratory mortality for children $<5$ years old resulted zero. Crude mortality rates (in deaths per 100000 people) for each age group and health outcomes were calculated. Table 2 describes population indicators and mortality rates by age group for the period of analysis.

\section{Concentration-response functions}

Epidemiological studies can use regression models that generate relative risk (RR) functions with a $\beta$-coefficient that relates the per cent change in the health outcome to a unit change in air pollutant concentration, that is, an increase of the risk per $10 \mu \mathrm{g} / \mathrm{m}^{3} \mathrm{PM}_{10}$. CRFs are equations derived from epidemiological studies that link the change in the number of adverse health effect incidences in a population to a change in pollutant concentration experienced by that population. Existing studies have reported either a $\beta$-coefficient or a RR. Additionally, 95\% CIs are provided for the $\beta$-coefficients and RR estimates in order to obtain upper and lower bounds of the health impacts. ${ }^{1} 820$

According to the WHO and depending on data availability, we used the recommended and alternative risk functions summarised in table 3 to calculate the RR for 
Table $1 \quad \mathrm{PM}_{10}$ and $\mathrm{O}_{3}$ concentration data set

\begin{tabular}{llllcccr}
\hline Pollutant & Year & $\begin{array}{l}\text { Number of } \\
\text { operating stations }\end{array}$ & $\begin{array}{l}\text { Operating stations } \\
\text { with valid data }\end{array}$ & Minimum & Maximum & Annual average & SD \\
\hline $\mathrm{PM}_{10}$ & 1999 & 7 & 2 & 44 & 47 & 45.5 & 2.121 \\
& 2000 & 7 & 7 & 33 & 47 & 41.6 & 5.127 \\
& 2001 & 7 & 4 & 38 & 46 & 42.7 & 3.695 \\
& 2002 & 8 & 4 & 25 & 39 & 33.3 & 5.909 \\
& 2003 & 6 & 6 & 23 & 39 & 30.2 & 6.853 \\
& 2004 & 6 & 4 & 33 & 52 & 39.5 & 8.583 \\
& 2005 & 6 & 6 & 31 & 49 & 36.2 & 6.911 \\
& 2006 & 6 & 5 & 30 & 41 & 36.4 & 4.393 \\
& 2007 & 5 & 4 & 20 & 31 & 25.6 & 4.159 \\
& 2008 & 6 & 4 & 22 & 26 & 23.3 & 1.893 \\
$\mathrm{O}_{3}$ & 1999 & 4 & 4 & 89 & 134 & 111.5 & 19.638 \\
& 2000 & 4 & 1 & 101 & 152 & 121.3 & 21.930 \\
& 2001 & 4 & 3 & 122 & 130 & 126 & 5.657 \\
& $2002^{*}$ & 3 & 3 & 126 & 168.7 & 147.3 & 30.169 \\
& 2003 & 4 & 3 & 165 & 174 & 168.7 & 4.726 \\
& 2004 & 3 & 3 & 142 & 164 & 149.7 & 12.423 \\
& 2005 & 3 & 3 & 146 & 159 & 154.7 & 7.506 \\
& 2006 & 3 & 3 & 138 & 151 & 142.7 & 7.234 \\
& 2007 & 3 & 137 & 146 & 143 & 5.196 \\
\hline
\end{tabular}

${ }^{*}$ In 20021 of 3 stations could provide valid data so it was decided to use the average of the years 2001 and 2003.

PM, particulate matter.

the following mortality outcomes associated with exposure to $\mathrm{PM}_{10}, \mathrm{PM}_{2.5}$ and $\mathrm{O}_{3 .}{ }^{18}{ }^{20}$ As not all of the listed outcomes can be reliably converted into DALYs (disability-adjusted life years) estimates and owing to data availability, preference was given to mortality instead of morbidity indicators or DALYs estimates as the health effect for this assessment. Short-term estimates should not be added to long-term estimates or estimates for children, since that would involve some double counting of the mortality cases. ${ }^{1}$
1. All-cause (natural) mortality associated with shortterm exposure to $\mathrm{PM}_{10}$ for all ages. ${ }^{1}$ These results should not be added to the other mortality estimates. DALYs cannot be determined for each of these premature deaths but can be used as an alternative to DALYs, and used as a basis for comparing short-term and long-term effects of pollutant exposure. ${ }^{1}$

2. All-cause (natural) and respiratory mortality in infants and children $<5$ years old related to shortterm exposure to $\mathrm{PM}_{10}{ }^{1}$ The application of this rate

Table 2 Population data and cause-specific mortality by age group (1999-2008)

\begin{tabular}{|c|c|c|c|}
\hline \multicolumn{4}{|l|}{ All ages } \\
\hline Population & All-cause (natural) mortality & Respiratory mortality & Cardiovascular mortality \\
\hline \multirow[t]{3}{*}{319.482} & 2.563 & 267 & 872 \\
\hline & Mortality rate* & & \\
\hline & 802 & 83 & 273 \\
\hline \multicolumn{4}{|l|}{$>30$ years } \\
\hline Population & All-cause (natural) mortality & Cardiopulmonary mortality & Lung cancer mortality \\
\hline \multirow[t]{3}{*}{212.702} & 2.535 & 729 & 142 \\
\hline & Mortality rate* & & \\
\hline & 1.192 & 342 & 67 \\
\hline \multicolumn{4}{|l|}{$<5$ years } \\
\hline Population & All-cause (natural) mortality & Respiratory mortality $\dagger$ & \\
\hline \multirow[t]{3}{*}{11.752} & 12 & 0 & \\
\hline & Mortality rate* & & \\
\hline & 100 & 2 & \\
\hline
\end{tabular}


Table 3 Health outcomes and risk functions used to calculate the burden of disease associated to $\mathrm{PM}_{10}, \mathrm{PM}_{2.5}$ and $\mathrm{O}_{3}$

\begin{tabular}{|c|c|c|c|c|}
\hline Outcome and exposure metric & RR function* & $\begin{array}{l}\text { B-coefficient/RR } \\
(95 \% \mathrm{Cl})\end{array}$ & Age group & ICD-10 codes \\
\hline All-cause (natural) mortality and short-term exposure to $\mathrm{PM}_{10}$ & $R R=\exp \left[\beta\left(X-X_{o}\right)\right]$ & $\begin{array}{l}0.0008^{1} \\
(0.0006 \text { to } 0.0010)\end{array}$ & All ages & All except V01-Y89 \\
\hline All-cause (natural) and respiratory mortality and short-term exposure to $\mathrm{PM}_{10} \dagger$ & $R R=\exp \left[\beta\left(X-X_{o}\right)\right]$ & $\begin{array}{l}0.00166^{1} \\
(0.00034 \text { to } 0.0030)\end{array}$ & $<5$ years & $\begin{array}{l}\text { All except V01-Y89/ } \\
\text { J00-J99 }\end{array}$ \\
\hline All cause (natural) mortality and long-term exposure to $\mathrm{PM}_{2.5}$ & $R R=\exp \left[\beta\left(X-X_{o}\right)\right]$ & $\begin{array}{l}1.062^{8} \\
(1.040 \text { to } 1.083)\end{array}$ & >30years & All except V01-Y89 \\
\hline Cardiopulmonary mortality and long-term exposure to $\mathrm{PM}_{2.5}$ (log-linear exposure)§ & $\left.R R=\left[(X+1) /\left(X_{0}\right)+1\right)\right]^{\beta}$ & $\begin{array}{l}0.15515^{1} \\
(0.0562 \text { to } 0.2541)\end{array}$ & $>30$ years & 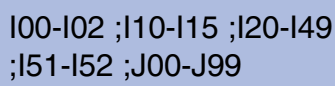 \\
\hline Cardiopulmonary mortality and long-term exposure to $\mathrm{PM}_{2.5}$ (linear exposure) & $\mathrm{RR}=\exp \left[\beta\left(\mathrm{X}-\mathrm{X}_{\circ}\right)\right]$ & $\begin{array}{l}0.00893^{1} \\
(0.00322-0.01464)\end{array}$ & $>30$ years & $\begin{array}{l}\text { I00-I02; I10-I15; ;20-I49 } \\
; 151-152 ; J 00-J 99\end{array}$ \\
\hline Lung cancer and long-term exposure to $\mathrm{PM}_{2.5}$ (log-linear exposure)§ & $\left.R R=\left[(X+1) /\left(X_{\circ}\right)+1\right)\right]^{\beta}$ & $\begin{array}{l}0.23218^{1} \\
(0.08563 \text { to } 0.37873)\end{array}$ & $>30$ years & C33-C34 \\
\hline Lung cancer and long-term exposure to $\mathrm{PM}_{2.5}$ (linear exposure) & $\mathrm{RR}=\exp \left[\beta\left(\mathrm{X}-\mathrm{X}_{\circ}\right)\right]$ & $\begin{array}{l}0.01267^{1} \\
(0.00432 \text { to } 0.02102)\end{array}$ & $>30$ years & С33-С34 \\
\hline All-cause mortality and short-term exposure to $\mathrm{O}_{3}$ & $R R=\exp [\beta(X-X o)]$ & $\begin{array}{l}1.002^{20} \\
(1.0005 \text { to } 1.0035) \\
1.0029^{8} \\
(1.0014 \text { to } 1.0043)\end{array}$ & All ages & All except V01-Y89 \\
\hline Respiratory mortality and short-term exposure to $\mathrm{O}_{3}$ & $R R=\exp [\beta(X-X o)]$ & $\begin{array}{l}0.999^{20} \\
(0.995 \text { to } 1.004) \\
1.0029^{8} \\
(0.9989 \text { to } 1.0070)\end{array}$ & All ages & J00-J99 \\
\hline Cardiovascular mortality and short-term exposure to $\mathrm{O}_{3}$ & $\mathrm{RR}=\exp [\beta(X-X o)]$ & $\begin{array}{l}1.004^{20} \\
(1.003 \text { to } 1.005) \\
1.0049^{8} \\
(1.0013 \text { to } 1.0085)\end{array}$ & All ages & $100-199$ \\
\hline
\end{tabular}

${ }^{*} X=$ current pollutant concentration $\left(\mu \mathrm{g} / \mathrm{m}^{3}\right)$ and $X_{\mathrm{o}}=$ target or threshold pollutant concentration $\left(\mu \mathrm{g} / \mathrm{m}^{3}\right)$.

$\dagger$ All-cause mortality for upper bound where applicable.

$\ddagger$ †Respiratory mortality.

$\S$ Recommended relationship.

ICD-10 codes, International Classification of Diseases 10th version; PM, particulate matter; RR, relative risk. 
to all-cause mortality could however represent an upper boundary of disease burden caused by outdoor air pollution, but may result in an overestimate when applied to certain regions. ${ }^{1}$

3. All-cause (natural) mortality associated with longterm exposure to $\mathrm{PM}_{2.5}$ for $>30$ years old. ${ }^{8}$ The recommended risk coefficient is based on the meta-analysis of cohort studies published by Hoek et $a l^{4}$ According to the HRAPIE report (2013), preference was given to use of the all-cause function instead of cause-specific indicators. ${ }^{8}$

4. Cardiopulmonary and lung cancer mortality related to long-term exposure to $\mathrm{PM}_{2.5}$ for $>30$ years old. ${ }^{1}$ The long-term estimate should not be added to the estimate for short-term exposure, since this would double count a portion, if not all, of the short-term cases. ${ }^{1}$

5. All-cause (natural), respiratory and cardiovascular mortality related to short-term exposure to $\mathrm{O}_{3}$ for all ages. ${ }^{8}{ }^{20}$ Using two different sets of risk coefficients estimates for the same outcomes (from Anderson et $a l$ and the HRAPIE report, 2013) enabled the results under these assumptions to be compared. The coefficients summarised by Anderson et $a l^{20}$ were revised for publication bias.

Examining the sensitivity of the results to alternative assumptions is recommended. ${ }^{1}$ A sensitivity analysis was conducted using alternative values for these parameters:

- $\mathrm{PM}_{2.5} / \mathrm{PM}_{10}$ ratio: an alternative ratio of $0.65^{18}$ that results in an estimated $\mathrm{PM}_{2.5}$ concentration of $23.01 \mu \mathrm{g} / \mathrm{m}^{3}$ was examined. This ratio is considered an average for the European population by the HRAPIE report. However, in specific locations the ratio may be in the range $0.4-0.8{ }^{8}$

- Background concentrations for $\mathrm{PM}_{2.5}$ and $\mathrm{O}_{3}{ }^{1}{ }^{3}{ }^{22}$ : 7.5 and $50 \mu \mathrm{g} / \mathrm{m}^{3}$, respectively.

- Shape of the CRF: for cardiopulmonary and lung cancer mortality associated with $\mathrm{PM}_{2.5}$ exposure a linear model was examined as an alternative to the recommended log-linear relationship. ${ }^{1}$

Those RR functions in table 3 compare current measured pollutant concentrations with a counterfactual level (a hypothetical 'natural' background or a 'target' concentration). Therefore, two kinds of calculations can be made $^{1}$ :

1. The total number of attributable deaths (ADs) due to current air pollution levels.

2. The number of deaths that could be prevented if the target concentration were achieved (targeted avoidable deaths, TADs).

The only difference between the two calculations is the counterfactual level used in (1) it is the 'natural' background level (ie, the level that would exist without any man-made pollution) and (2) it is a 'target' concentration. ${ }^{1}$ Different counterfactual concentrations were selected to reflect different exposure scenarios, as described following.
The counterfactual concentrations used for $\mathrm{PM}_{10}$ were:

- $10 \mu \mathrm{g} / \mathrm{m}^{3}$ : background level scenario. ${ }^{1}$

- $20 \mu \mathrm{g} / \mathrm{m}^{3}$ : target value scenario from the WHO Air Quality Guidelines (AQG). ${ }^{23}$

- $40 \mu \mathrm{g} / \mathrm{m}^{3}$ : target value scenario from the Directive $2008 / 50 /$ EC. $^{19}$

Four counterfactual concentrations were used for $\mathrm{PM}_{2.5}$ :

- $3 \mu \mathrm{g} / \mathrm{m}^{3}$ : background level scenario. ${ }^{1}$

- $10 \mu \mathrm{g} / \mathrm{m}^{3}$ : target value scenario from the WHO AQG. ${ }^{23}$

- $25 \mu \mathrm{g} / \mathrm{m}^{3}$ : target value scenario from the Directive $2008 / 50 /$ EC. $^{19}$

- $7.5 \mu \mathrm{g} / \mathrm{m}^{3}$ : alternative background level for sensitivity analysis. $^{122}$

Four counterfactual concentrations were used for $\mathrm{O}_{3}$ :

- $70 \mu \mathrm{g} / \mathrm{m}^{3}$ : background level scenario from the WHO AQG. ${ }^{23}$

- $100 \mu \mathrm{g} / \mathrm{m}^{3}$ : target value scenario from the WHO AQG. ${ }^{23}$

- $120 \mu \mathrm{g} / \mathrm{m}^{3}$ : target value scenario from the Directive $2008 / 50 /$ EC. $^{19}$

- $50 \mu \mathrm{g} / \mathrm{m}^{3}$ : alternative background level for sensitivity analysis. ${ }^{3}$

Once the RRs have been computed, the AF is determined in the classic attributable risk calculation ${ }^{1}$ :

$$
\mathrm{AF}=(\mathrm{RR}-1) / \mathrm{RR}
$$

Regarding $\mathrm{O}_{3}$ exposure, these $\mathrm{RR}$ estimates can be converted into an estimated $\beta$ using the following equation where $\Delta \mathrm{O}_{3}$ is a specified change in pollutant (ie, for a $10 \mu \mathrm{g} / \mathrm{m}^{3}$ increase $)^{24}$ :

$$
\beta=\operatorname{Ln}(\mathrm{RR}) / \Delta \mathrm{O}_{3}
$$

Then, the difference between current ozone ( $8 \mathrm{~h}$ mean) and a counterfactual level is used to calculate RR as follows ${ }^{24}$ :

$$
\mathrm{RR}=\exp \left(\beta \Delta \mathrm{O}_{3}\right)
$$

These RR estimates are subsequently applied to determine the $\mathrm{AF}$ as stated before. Ultimately, the expected number of deaths is calculated by ${ }^{1}$ :

$$
\mathrm{E}=\mathrm{AF} \times \mathrm{M} \times \mathrm{P}
$$

where $\mathrm{M}$, mortality rate; $\mathrm{P}$, exposed population size.

The previous steps come with a range of assumptions and uncertainties. To reflect these uncertainties results are presented with a point estimate as well as an upper and lower bound given by the 95\% CI of the CRF.ADs and TADs estimates were rounded off to the nearest whole number.

\section{RESULTS}

Table 4 shows the impact (in terms of mortality) of the estimated current ambient levels of pollutants relative to the assumed background concentrations and the benefit of reducing pollutant concentrations to the levels set as targets by the WHO AQG or the Directive 2008/50/EC. Our estimates point out that compliance with the WHO 
AQG target values might result in higher savings, in terms of mortality avoided, than with the Directive 2008/50/EC standards. Morbidity adverse health effects are not included in the assessment.
This table presents the annual number of ADs and TADs (deaths per year) for the period 1999-2008 along with their corresponding AFs (multiplied by 100 to express as percentage).

Table 4 Annual number of deaths (deaths per year) from outdoor air pollution for 1999-2008

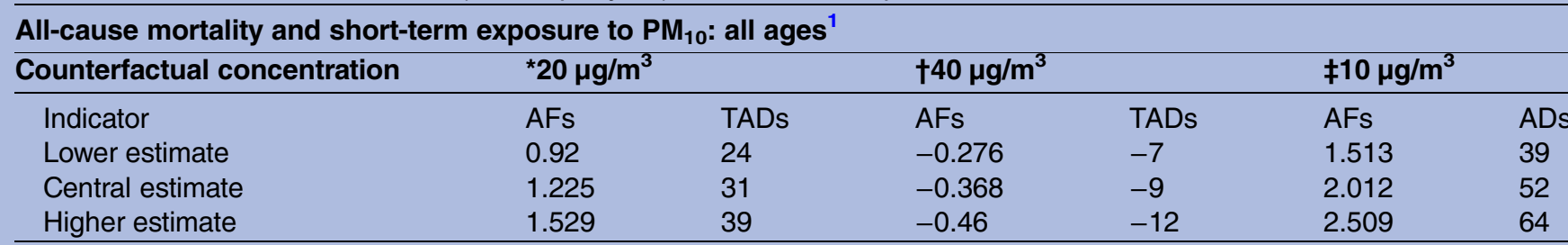

All-cause mortality and short-term exposure to $\mathrm{PM}_{10}$ : age $<5$ years*

\begin{tabular}{lllllll}
\hline Counterfactual concentration & $\mathbf{\$ 2 0} \boldsymbol{\mu g} / \mathbf{m}^{\mathbf{3}}$ & \multicolumn{1}{c}{} & $\mathbf{\$ 4 0} \boldsymbol{\mu g} / \mathbf{m}^{\mathbf{3}}$ & $\mathbf{\$ 1 0} \boldsymbol{\mu g} / \mathbf{m}^{\mathbf{3}}$ \\
\hline Indicator & AFs & TADs & AFs & TADs & AFs & ADs \\
Lower estimate & 0.523 & 0 & -0.156 & 0 & 0.86 & 0 \\
Central estimate & 2.526 & 0 & -0.765 & 0 & 4.13 & 0 \\
Higher estimate & 4.518 & 1 & -1.386 & 0 & 7.34 & 1
\end{tabular}

All-cause mortality and long-term exposure to $\mathrm{PM}_{2.5}$ : age $>30$ years ${ }^{8}$

\begin{tabular}{lllllll}
\hline Counterfactual concentration & ${ }^{*} \mathbf{1 0} \boldsymbol{\mu g} / \mathbf{m}^{\mathbf{3}}$ & & $\mathbf{\dagger 2 5} \boldsymbol{\mu \mathbf { g }} / \mathbf{m}^{\mathbf{3}}$ & & $\mathbf{\$ 3} \mathbf{\mu g} / \mathbf{m}^{\mathbf{3}}$ \\
\hline Indicator & AFs & TADs & AFs & TADs & AFs & ADs \\
Lower estimate & 6.027 & 153 & 0.333 & 8 & 8.572 & 217 \\
Central estimate & 9.094 & 231 & 0.510 & 13 & 12.842 & 326 \\
Higher estimate & 11.872 & 301 & 0.675 & 17 & 16.656 & 422
\end{tabular}

Cardiopulmonary mortality and long-term exposure to $\mathrm{PM}_{2.5}$ : age $>30$ years ${ }^{1}$

\begin{tabular}{|c|c|c|c|c|c|c|}
\hline Counterfactual concentration & ${ }^{*} 10 \mu \mathrm{g} / \mathrm{r}$ & & $\dagger 25 \mu$ & & $\ddagger 3 \mu \mathrm{g} / \mathrm{r}$ & \\
\hline Indicator & AFs & TADs & AFs & TADs & AFs & $A D s$ \\
\hline Lower estimate & 4.891 & 36 & 0.181 & 1 & 10.148 & 74 \\
\hline Central estimate & 12.929 & 94 & 0.498 & 4 & 25.577 & 186 \\
\hline Higher estimate & 20.288 & 148 & 0.814 & 6 & 38.356 & 280 \\
\hline
\end{tabular}

Lung cancer mortality and long-term exposure to $\mathrm{PM}_{2.5}$ : age $>30$ years ${ }^{1}$

\begin{tabular}{|c|c|c|c|c|c|c|}
\hline Counterfactual concentration & ${ }^{*} 10 \mu \mathrm{g} / \mathrm{r}$ & & $\dagger 25 \mu$ & & $\ddagger 3 \mu \mathrm{g} / \mathrm{n}$ & \\
\hline Indicator & AFs & TADs & AFs & TADs & AFs & $A D s$ \\
\hline Lower estimate & 7. 357 & 10 & 0.275 & 0 & 15.044 & 21 \\
\hline Central estimate & 18.713 & 27 & 0.744 & 1 & 35.729 & 51 \\
\hline Higher estimate & 28.678 & 41 & 1.211 & 2 & 51.378 & 73 \\
\hline
\end{tabular}

All-cause mortality and short-term exposure to $\mathrm{O}_{3}$ : all ages

\begin{tabular}{|c|c|c|c|c|c|c|}
\hline \multirow{2}{*}{$\begin{array}{l}\text { Counterfactual concentration } \\
\text { Indicator }\end{array}$} & \multicolumn{2}{|c|}{${ }^{*} 100 \mu \mathrm{g} / \mathrm{m}^{3}$} & \multicolumn{2}{|c|}{$+120 \mu g / m^{3}$} & \multicolumn{2}{|c|}{$\S 70 \mu \mathrm{g} / \mathrm{m}^{3}$} \\
\hline & AFs & TADs & AFs & TADs & AFs & ADs \\
\hline \multicolumn{7}{|c|}{ Source of risk estimates: Anderson et al ${ }^{20}$} \\
\hline Lower estimate & 0.207 & 5 & 0.107 & 3 & 0.356 & 9 \\
\hline Central estimate & 0.823 & 21 & 0.426 & 11 & 1.416 & 36 \\
\hline Higher estimate & 1.435 & 37 & 0.744 & 19 & 2.463 & 63 \\
\hline \multicolumn{7}{|c|}{ Source of risk estimates: HRAPIE Project ${ }^{8}$} \\
\hline Lower estimate & 0.577 & 15 & 0.299 & 8 & 0.994 & 25 \\
\hline Central estimate & 1.191 & 31 & 0.617 & 16 & 2.046 & 52 \\
\hline Higher estimate & 1.760 & 45 & 0.913 & 23 & 3.016 & 77 \\
\hline
\end{tabular}

Respiratory mortality and short-term exposure to $\mathrm{O}_{3}$ : all ages

\begin{tabular}{|c|c|c|c|c|c|c|}
\hline \multirow{2}{*}{$\begin{array}{l}\text { Counterfactual concentration } \\
\text { Indicator }\end{array}$} & \multicolumn{2}{|c|}{${ }^{*} 100 \mu \mathrm{g} / \mathrm{m}^{3}$} & \multicolumn{2}{|c|}{$\dagger 120 \mu g / \mathrm{m}^{3}$} & \multicolumn{2}{|c|}{$\S 70 \mu \mathrm{g} / \mathrm{m}^{3}$} \\
\hline & AFs & TADs & AFs & TADs & AFs & $A D s$ \\
\hline \multicolumn{7}{|c|}{ Source of risk estimates: Anderson et al ${ }^{20}$} \\
\hline Lower estimate & -2.096 & -6 & -1.077 & -3 & -3.642 & -10 \\
\hline Central estimate & -0.415 & -1 & -0.214 & -1 & -0.717 & -2 \\
\hline Higher estimate & 1.638 & 4 & 0.85 & 2 & 2.809 & 7 \\
\hline
\end{tabular}


Table 4 Continued

\begin{tabular}{|c|c|c|c|c|c|c|}
\hline \multicolumn{7}{|c|}{ Respiratory mortality and short-term exposure to $\mathrm{O}_{3}$ : all ages } \\
\hline Counterfactual concentration & \multicolumn{2}{|c|}{${ }^{*} 100 \mu \mathrm{g} / \mathrm{m}^{3}$} & \multicolumn{2}{|c|}{$+120 \mu g / m^{3}$} & \multicolumn{2}{|c|}{$\S 70 \mu \mathrm{g} / \mathrm{m}^{3}$} \\
\hline \multicolumn{7}{|c|}{ Source of risk estimates: HRAPIE Project ${ }^{8}$} \\
\hline Lower estimate & -0.456 & -1 & -0.236 & -1 & -0.789 & -2 \\
\hline Central estimate & 1.191 & 3 & 0.617 & 2 & 2.046 & 5 \\
\hline Higher estimate & 2.845 & 8 & 1.480 & 4 & 4.857 & 13 \\
\hline \multicolumn{7}{|c|}{ Cardiovascular mortality and short-term exposure to $\mathrm{O}_{3}$ : all ages } \\
\hline Counterfactual concentration & \multicolumn{2}{|c|}{${ }^{\star} 100 \mu \mathrm{g} / \mathrm{m}^{3}$} & \multicolumn{2}{|c|}{$+120 \mu \mathrm{g} / \mathrm{m}^{3}$} & \multicolumn{2}{|c|}{$\S 70 \mu \mathrm{g} / \mathrm{m}^{3}$} \\
\hline Indicator & AFs & TADs & AFs & TADs & AFs & ADs \\
\hline \multicolumn{7}{|c|}{ Source of risk estimates: Anderson et al ${ }^{20}$} \\
\hline Lower estimate & 1.232 & 11 & 0.638 & 6 & 2.115 & 18 \\
\hline Central estimate & 1.638 & 14 & 0.85 & 7 & 2.809 & 25 \\
\hline Higher estimate & 2.042 & 18 & 1.06 & 9 & 3.497 & 31 \\
\hline \multicolumn{7}{|c|}{ Source of risk estimates: HRAPIE Project ${ }^{8}$} \\
\hline Lower estimate & 0.536 & 5 & 0.277 & 2 & 0.923 & 8 \\
\hline Central estimate & 2.002 & 17 & 1.039 & 9 & 3.429 & 30 \\
\hline Higher estimate & 3.441 & 30 & 1.793 & 16 & 5.862 & 51 \\
\hline \multicolumn{7}{|c|}{$\begin{array}{l}\text { Counterfactual concentrations: } \\
\text { *Target concentration from WHO }{ }^{23} \\
\text { tTarget concentration from Directive 2008/50/EC. }{ }^{19} \\
\text { fBackground level from Ostro. }{ }^{1} \\
\text { §Background level from WHO. }{ }^{23} \\
\text { ADs, attributable deaths; AFs, attributable fractions; HRAPIE, Health risks of air pollution in Europe; PM, particulate matter; TADs, targeted } \\
\text { avoidable deaths. }\end{array}$} \\
\hline
\end{tabular}

As for the TADs, which estimate the number of deaths that could have been avoided in case of having reduced the air pollutant concentrations to the levels set as a target, the AFs estimate the proportional reduction of the mortality cause that could have been prevented in case of having decreased to the target scenario the exposure to the air pollutant. Regarding the ADs, which estimate the number of deaths due to current air pollution concentrations relative to the assumed background levels, the AFs estimate the proportion of the mortality cause that could have been attributed to those pollutants.

ADs and TADs estimates were rounded off to the nearest whole number. For this reason, zero values for ADs and TADs are calculated for all-cause mortality related to $\mathrm{PM}_{10}$ for $<5$ years and for lung cancer mortality related to $\mathrm{PM}_{2.5}$ in $>30$ years under the Directive 2008/50/EC exposure scenario $\left(25 \mu \mathrm{g} / \mathrm{m}^{3}\right)$. Negative estimates, which should be read as zero, were obtained when current pollutant concentrations were below the counterfactual value assumed (Directive 2008/50/EC exposure scenario for all-cause mortality related to exposure to $\mathrm{PM}_{10}$ ) or assumed risk coefficients were below 1 (for respiratory mortality related to exposure to $\mathrm{O}_{3}$ : the lower and central risk estimates revised for publication bias from Anderson et al and the lower risk estimate from HRAPIE project). Likewise, since annual average for 1999-2008 of respiratory mortality for children $<5$ years old was rounded off to zero, ADs and TADs estimates for respiratory mortality related to $\mathrm{PM}_{10}$ exposure for this age group resulted null and are not presented. It bears noting that AFs of respiratory mortality for children $<5$ years are the same as for all-cause mortality.

When applying the more stringent WHO target values scenarios, higher TADs and AFs estimates than under Directive 2008/50/EC exposure conditions were obtained. Overall, estimates for the mortality related to $\mathrm{PM}_{2.5}$ exposure were higher than for $\mathrm{PM}_{10}$ and $\mathrm{O}_{3}$. Specifically, for cardiopulmonary and lung cancer mortality associated to $\mathrm{PM}_{2.5}$ exposure, notable AFs were obtained and the CIs show quite a broader range than those for mortality related to $\mathrm{PM}_{10}$ and $\mathrm{O}_{3}$.

Concerning mortality associated to $\mathrm{O}_{3}$ exposure, central and higher estimates were slightly larger when assuming the risk coefficients derived from the HRAPIE project than those from Anderson et al. For respiratory mortality, negative estimates were obtained as described previously. CIs range is narrower than for mortality estimates associated to $\mathrm{PM}_{2.5}$. The overall picture from the two sets of coefficients assumed might be considered similar.

Table 5 provides the estimates for the different input parameters evaluated as a sensitivity analysis.

Overall, for long-term effects of $\mathrm{PM}_{2.5}$ exposure, the results remained within the range calculated on the basis of the recommended parameters. For the alternative $\mathrm{PM}_{2.5} / \mathrm{PM}_{10}$ ratio of 0.65 , negative TADs estimates were obtained as the counterfactual level of $25 \mu \mathrm{g} / \mathrm{m}^{3}$ (Directive 2008/50/EC) was higher than the estimated $\mathrm{PM}_{2.5}$ concentration of $23.01 \mu \mathrm{g} / \mathrm{m}^{3}$ for the alternative ratio. Broadly, estimates under the recommended ratio 
Table 5 Effects of alternative assumptions on annual number of deaths estimates (deaths per year)

\begin{tabular}{|c|c|c|c|c|c|c|c|c|}
\hline \multicolumn{9}{|c|}{ All-cause mortality and long-term exposure to $\mathrm{PM}_{2.5}$ : age $>30$ years ${ }^{8}$} \\
\hline \multirow[b]{2}{*}{ Counterfactual concentration } & \multicolumn{8}{|c|}{$\mathrm{PM}_{2.5} / \mathrm{PM}_{10}$ ratio: $0.73^{1}$} \\
\hline & \multicolumn{2}{|c|}{${ }^{*} 10 \mu \mathrm{g} / \mathrm{m}^{3}$} & \multicolumn{2}{|c|}{$\dagger 25 \mu \mathrm{g} / \mathrm{m}^{3}$} & \multicolumn{2}{|c|}{$\ddagger 3 \mu \mathrm{g} / \mathrm{m}^{3}$} & \multicolumn{2}{|c|}{$¥ \$ 7.5 \mu \mathrm{g} / \mathrm{m}^{3}$} \\
\hline Indicator & AFs & TADs & AFs & TADs & AFs & ADs & AFs & ADs \\
\hline Lower estimate & 6.027 & 153 & 0.333 & 8 & 8.572 & 217 & 6.944 & 176 \\
\hline Central estimate & 9.094 & 231 & 0.510 & 13 & 12.842 & 326 & 10.451 & 265 \\
\hline \multirow{2}{*}{ Higher estimate } & 11.872 & 301 & 0.675 & 17 & 16.656 & 422 & 13.611 & 345 \\
\hline & \multicolumn{8}{|c|}{$\mathrm{PM}_{2 \cdot 5} / \mathrm{PM}_{10}$ ratio: $0.65^{18}$} \\
\hline Lower estimate & 4.977 & 126 & -0.781 & -20 & 7.551 & 191 & 5.904 & 150 \\
\hline Central estimate & 7.532 & 191 & -1.200 & -30 & 11.344 & 288 & 8.912 & 226 \\
\hline Higher estimate & 9.859 & 250 & -1.594 & -40 & 14.752 & 374 & 11.638 & 295 \\
\hline
\end{tabular}

Cardiopulmonary mortality and long-term exposure to $\mathrm{PM}_{2.5}$ : age $>30$ years ${ }^{1}$ Log-linear relationship ${ }^{1}$

$\mathrm{PM}_{2.5} / \mathrm{PM}_{10}$ ratio: $0.73^{1}$

\begin{tabular}{|c|c|c|c|c|c|c|c|c|}
\hline \multirow{2}{*}{$\frac{\text { Counterfactual concentration }}{\text { Indicator }}$} & \multicolumn{2}{|c|}{${ }^{*} 10 \mu \mathrm{g} / \mathrm{m}^{3}$} & \multicolumn{2}{|c|}{$\dagger 25 \mathrm{~g} / \mathrm{m}^{3}$} & \multicolumn{2}{|c|}{$\ddagger 3 \mu \mathrm{g} / \mathrm{m}^{3}$} & \multicolumn{2}{|c|}{$\ddagger \S 7.5 \mu \mathrm{g} / \mathrm{m}^{3}$} \\
\hline & AFs & TADs & AFs & TADs & AFs & ADs & AFs & ADs \\
\hline Lower estimate & 4.891 & 36 & 0.181 & 1 & 10.148 & 74 & 6.26 & 46 \\
\hline Central estimate & 12.929 & 94 & 0.498 & 4 & 25.577 & 186 & 16.344 & 119 \\
\hline \multirow[t]{2}{*}{ Higher estimate } & 20.288 & 148 & 0.814 & 6 & 38.356 & 280 & 25.343 & 185 \\
\hline & \multicolumn{8}{|c|}{$\mathrm{PM}_{2.5} / \mathrm{PM}_{10}$ ratio: $0.65^{18}$} \\
\hline Lower estimate & 4.294 & 31 & -0.447 & -3 & 9.583 & 70 & 5.670 & 41 \\
\hline Central estimate & 11.410 & 83 & -1.238 & -9 & 24.278 & 177 & 14.884 & 109 \\
\hline \multirow[t]{2}{*}{ Higher estimate } & 17.997 & 131 & -2.036 & -15 & 36.585 & 267 & 23.198 & 169 \\
\hline & \multicolumn{8}{|c|}{$\begin{array}{l}\text { Linear relationship }{ }^{1} \\
\mathrm{PM}_{2.5} / \mathrm{PM}_{10} \text { ratio: } 0.73^{1}\end{array}$} \\
\hline Counterfactual concentration & \multicolumn{2}{|c|}{${ }^{*} 10 \mu \mathrm{g} / \mathrm{m}^{3}$} & \multicolumn{2}{|c|}{$\dagger 25 \mu \mathrm{g} / \mathrm{m}^{3}$} & \multicolumn{2}{|c|}{$\ddagger 3 \mu \mathrm{g} / \mathrm{m}^{3}$} & \multicolumn{2}{|c|}{$\ddagger \S 7.5 \mu \mathrm{g} / \mathrm{m}^{3}$} \\
\hline Indicator & AFs & TADs & AFs & TADs & AFs & ADs & AFs & ADs \\
\hline Lower estimate & 4.976 & 36 & 0.273 & 2 & 7.094 & 52 & 5.738 & 42 \\
\hline Central estimate & 13.198 & 96 & 0.756 & 6 & 18.458 & 135 & 15.114 & 110 \\
\hline \multirow[t]{2}{*}{ Higher estimate } & 20.709 & 151 & 1.237 & 9 & 28.432 & 207 & 23.558 & 172 \\
\hline & \multicolumn{8}{|c|}{$\mathrm{PM}_{2.5} / \mathrm{PM}_{10}$ ratio: $0.65^{18}$} \\
\hline Lower estimate & 4.105 & 30 & -0.641 & -5 & 6.242 & 46 & 4.874 & 36 \\
\hline Central estimate & 10.974 & 80 & -1.786 & -13 & 16.369 & 119 & 12.940 & 94 \\
\hline Higher estimate & 17.351 & 126 & -2.945 & -21 & 25.402 & 185 & 20.322 & 148 \\
\hline
\end{tabular}

Lung cancer mortality and long-term exposure to $\mathrm{PM}_{2.5}$ : age $>30$ years ${ }^{1}$

\begin{tabular}{|c|c|c|c|c|c|c|c|c|}
\hline \multirow{3}{*}{$\begin{array}{l}\text { Counterfactual concentration } \\
\text { Indicator }\end{array}$} & \multicolumn{8}{|c|}{$\begin{array}{l}\text { Log-linear relationship }{ }^{1} \\
\mathrm{PM}_{2.5} / \mathrm{PM}_{10} \text { ratio: } 0.73^{1}\end{array}$} \\
\hline & \multicolumn{2}{|c|}{${ }^{*} 10 \mu \mathrm{g} / \mathrm{m}^{3}$} & \multicolumn{2}{|c|}{$\dagger 25 \mu \mathrm{g} / \mathrm{m}^{3}$} & \multicolumn{2}{|c|}{$\ddagger 3 \mu \mathrm{g} / \mathrm{m}^{3}$} & \multicolumn{2}{|c|}{$\ddagger \$ 7.5 \mu \mathrm{g} / \mathrm{m}^{3}$} \\
\hline & AFs & TADs & AFs & TADs & AFs & ADs & AFs & ADs \\
\hline Lower estimate & 7.357 & 10 & 0.275 & 0 & 15.044 & 21 & 9.38 & 13 \\
\hline Central estimate & 18.713 & 27 & 0.744 & 1 & 35.729 & 51 & 23.437 & 33 \\
\hline \multirow[t]{2}{*}{ Higher estimate } & 28.678 & 41 & 1.211 & 2 & 51.378 & 73 & 35.313 & 50 \\
\hline & \multicolumn{8}{|c|}{$\mathrm{PM}_{2.5} / \mathrm{PM}_{10}$ ratio: $0.65^{18}$} \\
\hline Lower estimate & 6.468 & 9 & -0.682 & -1 & 14.229 & 20 & 8.510 & 12 \\
\hline Central estimate & 16.582 & 24 & -1.859 & -3 & 34.044 & 48 & 21.429 & 30 \\
\hline \multirow[t]{2}{*}{ Higher estimate } & 25.602 & 36 & -3.050 & -4 & 49.281 & 70 & 32.523 & 46 \\
\hline & \multicolumn{8}{|c|}{$\begin{array}{l}\text { Linear relationship }{ }^{1} \\
\mathrm{PM}_{2.5} / \mathrm{PM}_{10} \text { ratio: } 0.73^{1}\end{array}$} \\
\hline Counterfactual concentration & \multicolumn{2}{|c|}{${ }^{*} 10 \mu \mathrm{g} / \mathrm{m}^{3}$} & \multicolumn{2}{|c|}{$\dagger 25 \mu \mathrm{g} / \mathrm{m}^{3}$} & \multicolumn{2}{|c|}{$\ddagger 3 \mu \mathrm{g} / \mathrm{m}^{3}$} & \multicolumn{2}{|c|}{$\ddagger \$ 7.5 \mu \mathrm{g} / \mathrm{m}^{3}$} \\
\hline Indicator & AFs & TADs & AFs & TADs & AFs & ADs & AFs & ADs \\
\hline Lower estimate & 6.618 & 9 & 0.367 & 1 & 9.4 & 13 & 7.621 & 11 \\
\hline Central estimate & 18.194 & 26 & 1.071 & 2 & 25.137 & 36 & 20.745 & 29 \\
\hline Higher estimate & 28.335 & 40 & 1.771 & 3 & 38.141 & 54 & 32.004 & 45 \\
\hline
\end{tabular}


Table 5 Continued

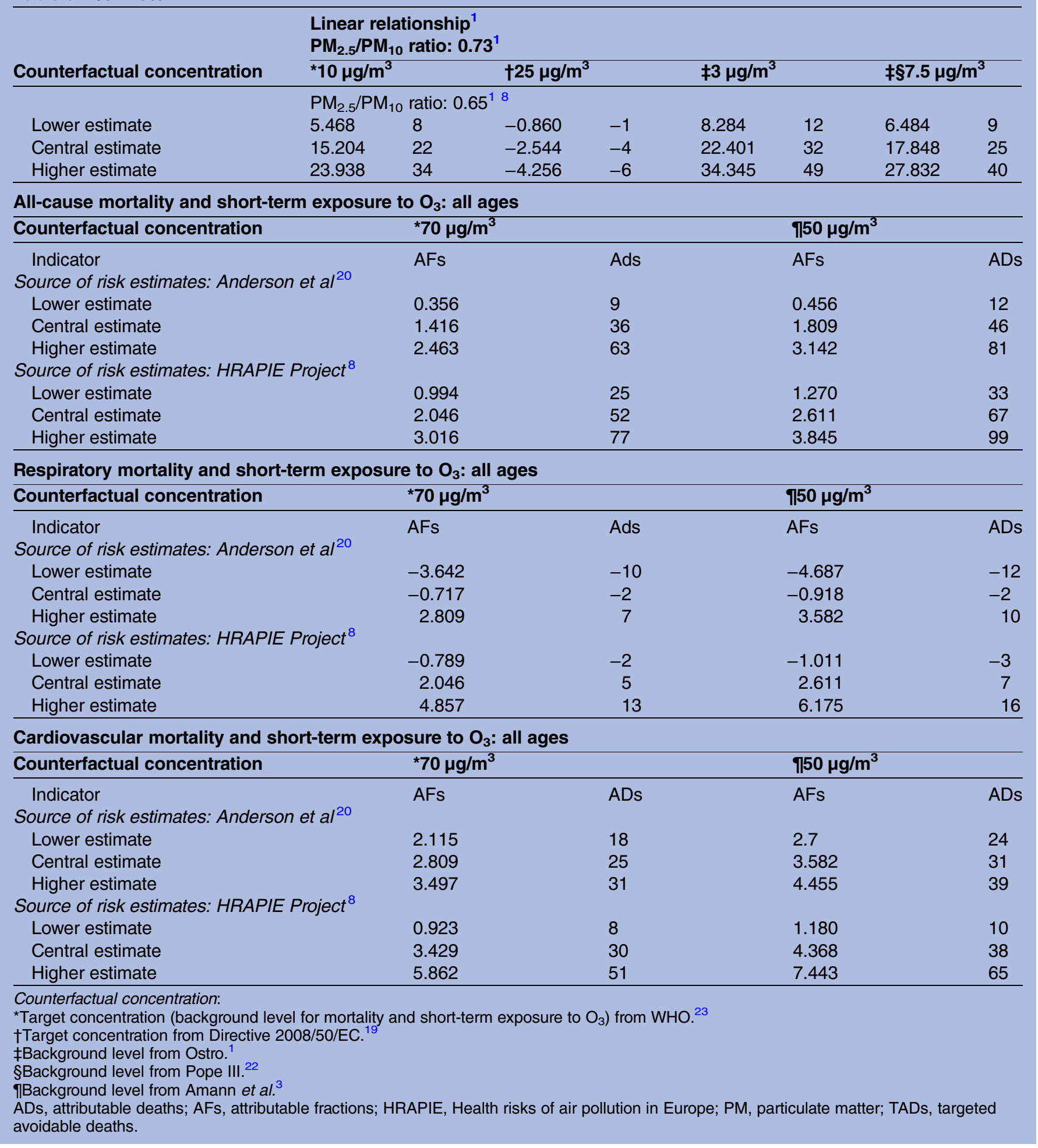

of 0.73 were higher than under the alternative assumption of 0.65 .

Regarding the shape of the model, slightly higher estimates were obtained under the recommended log-linear model. As for the alternative background level of $7.5 \mu \mathrm{g} / \mathrm{m}^{3}$, lower estimates than for the recommended background concentration of $3 \mu \mathrm{g} / \mathrm{m}^{3}$ were calculated.
Concerning mortality associated with short-term exposure to $\mathrm{O}_{3}$, slightly higher ADs estimates than for the suggested background level of $70 \mu \mathrm{g} / \mathrm{m}^{3}$ were obtained under the alternative background level of $50 \mu \mathrm{g} / \mathrm{m}^{3}$ for both sets of risk coefficients. Negative estimates were also obtained as described before. 


\section{DISCUSSION}

This HIA study pointed to a detrimental effect on mortality from $\mathrm{PM}_{10}, \mathrm{PM}_{2.5}$ and $\mathrm{O}_{3}$ exposure. Our estimates indicated a higher number of avoidable deaths from reducing pollutant concentrations to the WHO AQG levels than from a reduction to the European Union (EU) standards. The impact would have been greater if attainment of the legal standards at the moment had not been achieved.

When negative or null estimates were obtained, no deaths would have been possible to attribute or prevent relative to the exposure scenarios considered.

\section{Comparison with other studies}

HIA is an underutilised tool in Spain. ${ }^{25}$ To the best of our knowledge, there are no Spanish studies that have followed this EBD series guideline on outdoor air pollution. ${ }^{1}$ Estimates of the burden of disease associated to air pollution were calculated in various Spanish cities within the framework of different European ${ }^{26-28}$ and Spanish ${ }^{29-45}$ projects. A study estimated the health and economic benefits resulting from two scenarios of improved air quality (EU standards and WHO targets) in Barcelona. ${ }^{46}$ Two recent studies estimated the number of avoidable deaths associated with reducing $\mathrm{PM}_{2.5}$ in Spain. ${ }^{47} 48$ The heterogeneity of exposure data and methods used in the studies conducted in Spain do not let compare properly their results with our estimates. However, our estimates follow the trend showed by the literature.

\section{Strengths and weaknesses of this study}

This type of analysis has a range of inherent uncertainties and methodological limitations that must be considered when interpreting our estimates. Limitations can affect every step of the method. ${ }^{1}$

CIs only cover statistical uncertainty related to the risk estimates.Our estimates are sensitive to the alternative assumptions for $\mathrm{PM}_{2.5} / \mathrm{PM}_{10}$ ratio, background concentration and shape of CRF. Although the risk parameters are never completely transferable from one population to another, the methods and CRFs summarised by the WHO applied in our study provide the most appropriate, albeit imperfect, effect estimates. The methodology described in the current EBD series can be adapted both to local and national levels. The updated guidance and risk coefficients arising from the review process coordinated by the WHO would provide more accurate estimates of the impact on health that will be used to revise our results.

Caution must be taken as short-term estimates should not be added to long-term estimates or estimates for children since adding them would involve double count. ${ }^{1}$ As mentioned previously, the estimates for allcause mortality associated with short-term exposure to $\mathrm{PM}_{10}$ for $<5$ years might result in an overestimate. ${ }^{1}$ Probably no deaths would have been possible to attribute or prevent in children $<5$ years old related to short-term exposure to $\mathrm{PM}_{10}$. It should be emphasised that the HRAPIE report indicates that generalisation of the recommended approaches to other regions of the globe or individual countries, or to particular mixtures at the local level, may be not appropriate. Specifically, risk estimates for certain health outcomes exhibit more uncertainty. It bears noting that the background national data on all-cause mortality have greater precision than the cause-specific data. The latter may be affected by misclassification of causes of death in mortality registration. ${ }^{8}$

Our estimates of mortality associated to long-term exposure to $\mathrm{PM}_{2.5}$ show quite a large range. Reality is likely to lie in between. Probably differences in mortality rates and the proportion of population in age groups affect our results. Likely a data set including a longer period of analysis would have provided a better scope of the real impact of $\mathrm{PM}_{2.5}$.

Regarding the ambient exposure of the population, our results are affected by the ecological fallacy because of using ecological data on exposure to pollutants. We have also underestimated the effect of outdoor air pollution as morbidity adverse health effects, which impose a considerable health burden, are not included in the assessment. Similarly, assuming independence of the effects of pollutants could overestimate our results.

Our data (described in table 1) are based on a network of fixed-site monitors whose location, number and range of pollutants measured have changed over time, decreasing the quality and robustness of our exposure estimates. Equally, the effect on averages of outliers, street canyon effect and hot spot sites can overestimate our results.

Likewise, $\mathrm{PM}_{10}$ concentration data corrected for sub-Saharan dust intrusions were not available. In the absence of local data on fine particle matter, $\mathrm{PM}_{2.5}$ levels were estimated from the recommended $\mathrm{PM}_{2.5} / \mathrm{PM}_{10}$ ratio. ${ }^{1}$ There is a lack of a municipal emission source inventory and of local data for background levels of the pollutants considered in our study. In addition, the impact of other co-pollutants and seasonal effects (for instance the strong seasonal cycle for $\mathrm{O}_{3}$, high in summer and low in winter) can influence our estimates. Therefore, although presenting our results with a CI can provide a range for our estimates and set bounds to statistical error, we cannot diminish the uncertainty embodied in our results by the quality of the exposure data and our assumptions to estimate population exposure.

\section{Meaning of the study and directions for future research}

The WHO EBD series framework seems to prove useful to apply at local level. Our estimates, although constrained by major uncertainties, should be a quantitative input to local authorities become aware of the magnitude of the problem, help realise the substantial potential health benefits from compliance with WHO AQG target values and prioritise actions on strengthening control of outdoor air pollution. 
Local governments, through policies aimed mainly to reduce emissions from urban transport that provide alternatives to private motor vehicle traffic, could achieve considerable health gains. It must be stressed that these strategies, through synergies between policies, may yield other important co-benefits for health in traffic injury prevention, noise reduction, creation of spaces for exercise and recreation, etc. ${ }^{1}$ Actions should be taken to provide the population with this kind of information, since their awareness and active participation are basic to reduce air pollution.

As implications for future research, the recommendations and risk coefficients resulting from the current evidence review process led by the WHO will be used to revise and update our estimates. Likewise, the analysis with local measurements of $\mathrm{PM}_{2.5}$ to reduce uncertainty of estimates related to this pollutant should also be conducted. Collective efforts for developing the availability of morbidity data are needed in order to improve the evaluation of the burden of disease. Future research on improving the monitoring and description of the urban atmosphere and the background levels of pollutants in our local and regional setting should be developed.

\section{Conclusions}

Our study suggests a not negligible impact on mortality of outdoor air pollution by $\mathrm{PM}_{10}, \mathrm{PM}_{2.5}$ and $\mathrm{O}_{3}$. The implementation of the EBD series guideline on outdoor air pollution ${ }^{1}$ compiled by the WHO provides critical information to distinguish an improvement range in air pollution control.

Our results support a reflection on the opportunities to develop feasible actions in order to adopt the more stringent WHO targets, yielding more benefits than simply attaining the current Directive 2008/50/EC, and to enhance the monitoring of ambient air quality at local level.

In any case, we cannot forget that small reductions in the levels of risk factors may yield a great benefit for the health of the entire population.

Acknowledgements The authors thank Dr Annette Prüss-Üstün and Dr Sophie Bonjour from the WHO for the provision of the spreadsheet and valuable comments on its use, the Environmental Health Unit of the city of Valladolid for the provision of data on air pollution. The authors would also like to thank King Philip III of Spain for moving the capital city of Spain from Valladolid to Madrid in 1606 facilitating unconsciously the future feasibility of long-term air pollution control strategies.

Contributors MCA had the idea for this study from his doctoral thesis, leading the design, exposure assessment, data analysis and drafting of the manuscript. MFMM contributed to the exposure assessment, data analysis and the statistical script. AAM, MAC, FCV and AAG contributed to the exposure assessment and data analysis. All authors contributed to the critical reading of and comments to the manuscript, interpretation of data and approved the final draft. MCA is the guarantor.

Disclaimer The views expressed herein can in no way be taken to reflect the official opinion of the Environmental Health Unit of the city of Valladolid.

Funding This research received no specific grant from any funding agency in the public, commercial or not-for-profit sectors.

Competing interests None.
Provenance and peer review Not commissioned; externally peer reviewed.

Data sharing statement Extra data can be accessed via the Dryad data repository at http://datadryad.org/ with the doi:10.5061/dryad.3p4f3.

Open Access This is an Open Access article distributed in accordance with the Creative Commons Attribution Non Commercial (CC BY-NC 4.0) license, which permits others to distribute, remix, adapt, build upon this work noncommercially, and license their derivative works on different terms, provided the original work is properly cited and the use is non-commercial. See: http:// creativecommons.org/licenses/by-nc/4.0/

\section{REFERENCES}

1. Ostro B. Outdoor air pollution: assessing the environmental burden of disease at national and local levels. Geneva: World Health Organization. 2004. (WHO. Environmental Burden of Disease Series.No. 5). http://www.who.int/quantifying_ehimpacts/publications/ ebd5/en/ (accessed 12 Apr 2014).

2. Amann M, Derwent $D$, Forsberg $B$, et al. Health risks of particulate matter from long-range transboundary air pollution. Copenhagen: World Health Organization, Regional Office for Europe, 2006. http:// www.euro.who.int/en/health-topics/environment-and-health/airquality/publications/pre2009/health-risks-of-particulate-matter-fromlong-range-transboundary-air-pollution (accessed 12 Apr 2014).

3. Amann M, Derwent D, Forsberg B, et al. Health risks of ozone from long-range transboundary air pollution. Copenhagen, World Health Organization, Regional Office for Europe, 2008. http://www.euro. who.int/en/publications/abstracts/health-risks-of-ozone-from-longrange-transboundary-air-pollution (accessed $12 \mathrm{Apr} 2014$ ).

4. Hoek G, Krishnan RM, Beelen R, et al. Long-term air pollution exposure and cardio- respiratory mortality: a review. Environ Health 2013;12:43.

5. Beelen R, Raaschou-Nielsen O, Stafoggia M, et al. Effects of longterm exposure to air pollution on natural-cause mortality: an analysis of 22 European cohorts within the multicentre ESCAPE project. Lancet 2014;383:785-95.

6. Burnett RT, Pope CA III, Ezzati M, et al. An integrated risk function for estimating the global burden of disease attributable to ambient fine particulate matter exposure. Environ Health Perspect 2014;122:397-403.

7. Review of evidence on health aspects of air pollution-REVIHAAP project. Technical report. World Health Organization 2013. http:// www.euro.who.int/en/health-topics/environment-and-health/airquality/activities/health-aspects-of-air-pollution-and-review-of-eupolicies-the-revihaap-and-hrapie-projects (accessed 12 Apr 2014).

8. Health risks of air pollution in Europe-HRAPIE project. Recommendations for concentration-response functions for costbenefit analysis of particulate matter, ozone and nitrogen dioxide. World Health Organization. 2013. http://www.euro.who.int/en/healthtopics/environment-and-health/air-quality/activities/health-aspects-ofair-pollution-and-review-of-eu-policies-the-revihaap-and-hrapieprojects (accessed 12 Apr 2014).

9. http://www.who.int/gho/phe/outdoor_air_pollution/burden_text/en/ (accessed 12 Apr 2014).

10. http://www.iarc.fr/en/media-centre/iarcnews/pdf/pr221_E.pdf (accessed 12 Apr 2014).

11. Prüss-Üstün $A$, Corvalán $C$. Preventing disease through healthy environments. Towards an estimate of the environmental burden of disease. WHO, 2006. http://www.who.int/quantifying_ehimpacts/ publications/preventingdisease/en/ (accessed 12 Apr 2014).

12. Prüss-Üstün A, Mathers $C$, Corvalán $C$, et al. Introduction and methods: assessing the environmental burden of disease at national and local levels. Geneva: World Health Organization, 2003. (WHO Environmental Burden of Disease Series, No.1). http://www.who.int/ quantifying_ehimpacts/publications/9241546204/en/ (accessed 12 Apr 2014)

13. Diéguez Rodríguez JJ, Muñoz MM, Padilla Gómez L, et al. «Estudio y evaluación de la contaminación atmosférica por ozono troposférico en España ». 2009. Informe final. Ministerio de Medio Ambiente y Medio Rural y Marino. http://www.magrama.gob.es/es/calidad-yevaluacion-ambiental/temas/atmosfera-y-calidad-del-aire/calidad-delaire/estudios/ (accessed 6 Aug 2014).

14. Mogo S, Cachorro VE, De Frutos, AM. Morphological, chemical and optical absorbing characterization of aerosols in the urban atmosphere of Valladolid. Atmos Chem Phys 2005;5:2739-48.

15. http://www10.ava.es/rccava/03contaminantes2.html (accessed 6 Aug 2014).

16. http://www10.ava.es/rccava/08biblioteca1.html (accessed 14 Dec 2013).

17. Directive1999/30/EC. http://ec.europa.eu/environment/air/quality/ legislation/existing_leg.htm (accessed 28 Feb 2014). 
18. Directive 2000/69/EC. http://ec.europa.eu/environment/air/quality/ legislation/existing_leg.htm (accessed 28 Feb 2014).

19. Directive 2008/50/EC. http://ec.europa.eu/environment/air/quality/ standards.htm (accessed 28 Feb 2014)

20. Anderson HR, Atkinson RW, Peacock JL, et al. Meta-analysis of time-series studies and panel studies of particulate matter (PM) and ozone (O3). Report of a WHO task group. 2004. http://www.euro. who.int/en/health-topics/environment-and-health/air-quality/ publications/pre2009/meta-analysis-of-time-series-and-panel-studiesof-particulate-matter-and-ozone (accessed 12 Apr 2014).

21. http://www.ine.es/en/welcome.shtml (accessed 14 Dec 2013).

22. Pope CA III, Thun MJ, Namboodiri MM, et al. Particulate air pollution as a predictor of mortality in a prospective study of US adults. Am J Respir Crit Care Med. 1995;151:669-74.

23. WHO Air Quality Guidelines for particulate matter, ozone, nitrogen dioxide and sulfur dioxide. Global update 2005.Summary of risk assessment. WHO. 2006. http://www.who.int/phe/health_topics/ outdoorair/outdoorair_aqg/en/ (accessed 12 Apr 2014).

24. California Environmental Protection Agency. Air Resources Board. Review of the California ambient air quality standard for ozone. Volume IV of IV. Appendices B-G.Staff Report. Initial statement of reasons for proposed rulemaking. 27 October 2005. http://www.arb. ca.gov/carbis/research/aaqs/ozone-rs/rev-staff/vol4.pdf (accessed 12 Apr 2014).

25. Boldo E, Aragonés N, Medina S, et al. Evaluación de Impacto en Salud: una herramienta infrautilizada en salud pública. Ejemplo Apheis (Air Pollution and Health: a European Information System). Bol Epidemiol Sem 2005;13:97-108. http://gesdoc.isciii.es/ gesdoccontroller?action=download\&id=06/03/2013-9bf3a16ce7 (accessed 12 Apr 2014).

26. Touloumi G, Katsouyanni K, Zmirou D, et al. Short-term effects of ambient oxidant exposure on mortality: a combined analysis within the APHEA project. Am J Epidemiol 1997;146:177-85.

27. Katsouyanni K, Touloumi G, Samoli E, et al. Confounding and effect modification in the short-term effects of ambient particles on total mortality: results from 29 European cities within the APHEA 2 project. Epidemiology 2001;12:521-31.

28. Le Tertre A, Medina S, Samoli E, et al. Short-term effects of particulate air pollution on cardiovascular diseases in eight European cities. J Epidemiol Community Health 2002;56:773-9.

29. Ballester F, Corella D, Pérez-Hoyos S, et al. Air pollution and mortality in Valencia, Spain: a study using the APHEA methodology. $J$ Epidemiol Community Health 1996;50:527-33.

30. Ballester $\mathrm{F}$, Rodríguez $\mathrm{P}$, Iñíguez $\mathrm{C}$, et al. Air pollution and cardiovascular admissions association in Spain: results within the EMECAS project. J Epidemiol Community Health 2006;60:328-36.

31. Sunyer J, Antó JM, Murillo C, et al. Effects of urban air pollution on emergency room admissions for chronic obstructive pulmonary disease. Am J Epidemiol 1991;134:277-86.

32. Sunyer J, Basagaña X. Particles, and not gases, are associated with the risk of death in patients with chronic obstructive pulmonary disease. Int J Epidemiol 2001;30:1138-40.

33. Guillén Pérez JJ, Guillén Grima F, Medrano Tortosa J, et al. Afluencia inusual por asma y enfermedad pulmonar obstructiva crónica en urgencias hospitalarias y contaminación por SO2 en Cartagena. Rev Esp Salud Publica 1995;69:305-14.

34. Tenías JM, Ballester F, Rivera ML. Association between hospital emergency visits for asthma and air pollution in Valencia, Spain. Occup Environ Med 1998;55:541-7.

35. Ballester F, Iniguez C, Pérez-Hoyos S, et al. Polución atmosférica particulada y salud en Valencia. España. 1994-1996. Gac Sanit 2002;16:464-79.

36. Galan I, Tobías A, Banegas JR, et al. Short-term effects of air pollution on daily asthma emergency room admissions. Eur Respir $J$ 2003;22:802-8.

37. Sunyer J, Castellsagué J, Sáez M, et al. Air pollution and mortality in Barcelona. J Epidemiol Community Health 1996;50(Suppl 1): s76-80.

38. Tobías A, Sunyer J, Castellsague J, et al. Impacto de la contaminación atmosférica sobre la mortalidad y las urgencias por enfermedad pulmonar obstructiva crónica y asma en Barcelona. Gac Sanit 1998;12:223-30.

39. Sunyer J, Basagana X, Belmonte $\mathrm{J}$, et al. Effect of nitrogen dioxide and ozone on the risk of dying in patients with severe asthma. Thorax 2002;57:687-93.

40. Sunyer J, Schwartz J, Tobías A, et al. Patients with chronic obstructive pulmonary disease are at increased risk of death associated with urban particle air pollution: a case-crossover analysis. Am J Epidemiol 2000;151:50-6.

41. Ballester Diez F, Sáez Zafra M, Alonso Fustel ME, et al. El proyecto EMECAM: estudio multicéntrico español sobre la relación entre la contaminación atmosférica y la mortalidad. Antecedentes, participantes, objetivos y métodología. Rev Esp Salud Pública 1999;73:165-75.

42. Ballester F, Sáez M, Pérez-Hoyos S, et al. The EMECAM project: a multicentre study on air pollution and mortality in Spain: combined results for particulates and for sulfur dioxide. Occup Environ Med 2002;59:300-8.

43. Alonso Fustel E, Martínez Rueda T, Cambra Contín K, et al. Evaluación en cinco ciudades españolas del impacto en salud de la contaminación atmosférica por partículas. Proyecto europeo APHEIS. Rev Esp Salud Publica 2005;79:297-308.

44. Boldo E, Medina S, LeTertre A, et al. Apheis: health impact assessment of long-term exposure to $\mathrm{PM}(2.5)$ in 23 European cities. Eur J Epidemiol 2006;21:449-58.

45. Ballester F, Medina S, Boldo E, et al. Reducing ambient levels of fine particulates could substantially improve health: a mortality impact assessment for 26 European cities. J Epidemiol Community Health 2008;62:98-105

46. Pérez L, Sunyer J, Künzli N. Estimating the health and economic benefits associated with reducing air pollution in the Barcelona metropolitan area (Spain). Gac Sanit 2009;23:287-94.

47. Boldo E, Linares C, Lumbreras J, et al. Health impact assessment of a reduction in ambient $\mathrm{PM}_{25}$ levels in Spain. Environ Int 2011;37:342-8.

48. Boldo $\mathrm{E}$, Linares $\mathrm{C}$, Aragonés $\mathrm{N}$, et al. Air quality modeling and mortality impact of fine particles reduction policies in Spain. Environ Res 2014;128:15-26. 